\title{
DESAFIOS ENFRENTADOS PELOS EDUCADORES DO CAMPO DO NORTE DE MINAS GERAIS
}

\author{
Flávia Marques Alencar ${ }^{1}$ \\ Vania Guedes Silva ${ }^{2}$ \\ Juciara Oliveira Lopes ${ }^{3}$ \\ Miriam Cristina Schmidt Priebe ${ }^{4}$
}

Resumo: O objetivo da pesquisa se constituiu em analisar as trajetórias de professores de escolas rurais, e, a partir de suas experiências vividas, identificar quais problemas e desafios enfrentados, e quais as possibilidades de mudanças. Justifica-se essa pesquisa pela necessidade de demonstrar o quadro atual das escolas localizadas no campo, bem como apresentar perspectivas de mudanças, sinalizadas a partir dos movimentos sociais do campo, que reivindicam outro tipo de escola e de educação. A pesquisa seguiu uma abordagem qualitativa, com a aplicação de questionários abertos a quatro professores que possuem experiência de trabalho em escolas localizadas na zona rural, em cidades da região Norte de Minas Gerais. Ficou evidente a precariedade das escolas localizadas no campo, assim como a dificuldade de acesso e a rotatividade de professores.

Palavras-chave: Educação do campo; Escolas rurais; Professores das escolas do campo.

\footnotetext{
1 Educação/INCISOH, Brasil. E-mail: flavinha87@yahoo.com.br.

2 Educação/INCISOH, Brasil. E-mail: vaniaguedessilva@hotmail.com.

3 Engenharia Agrícola/IFNMG/Brasil. E-mail: juciaraoliveiralopes@yahoo.com.br.

${ }^{4}$ Educação/INCISOH, Brasil. E-mail: miriamcsp@hotmail.com.
} 